\title{
A presença de Nietzsche na produção intelectual e literária de Albertina Bertha
}

\author{
Anna Faedrich*
}

\begin{abstract}
Resumo: Neste texto analiso a presença da filosofia de Nietzsche na obra literária e intelectual da escritora carioca Albertina Bertha de Lafayette Stockler (1880-1953). O interesse e a paixão da escritora pelo filósofo alemão são demonstrados em referências, epígrafes e citações do filósofo. A discussão de Nietzsche por Bertha guarda interesse histórico por ser raro uma mulher frequentar fóruns filosóficos em pé de igualdade com homens, no Brasil, à época. Além da célebre conferência de 1914, que virou capítulo do livro Estudos (1920), as noções nietzschianas permeiam os escritos de Albertina Bertha, tanto nos romances, como nos ensaios.

Palavras-chave: Nietzsche, Albertina Bertha, Literatura Brasileira, Filosofia.
\end{abstract}

* Professora da Universidade Federal Fluminense, Niterói, RJ, Brasil.

ORCID https://orcid.org/0000-0001-6616-3812

Correio eletrônico: anna.faedrich@gmail.com 
Faedrich, A.

Albertina Bertha de Lafayette Stockler (Rio de Janeiro, 18801953) foi uma importante escritora carioca, romancista e ensaísta, na virada do século XIX para o século XX. Sua obra impressa é composta por cinco volumes, três romances - Exaltação (1916), Voleta (1926) e E ela brincou com a vida (1938) -, e dois livros de ensaios - Estudos (1920), e Estudos, segunda série (1948). Além dos volumes impressos, vale destacar sua expressiva participação em espaço privilegiado na imprensa periódica - em jornais como O Paiz, Jornal do Commercio, O Jornal, O Malho, A Noite -, o que atesta a posição de prestígio e de respeito da autora em ambiente intelectual e literário eminentemente masculino. Como outras escritoras, Albertina Bertha contribuiu de modo relevante para o acervo das Letras no Brasil, mas foi esquecida pela história literária nacional, que raramente incorpora mulheres em seu cânone.

Filha do Conselheiro Lafayette Rodrigues Pereira ${ }^{\mathbf{l}}$ e de Francisca de Freitas Coutinho Lafayette, neta dos Barões de Pouso Alegre, Albertina Bertha usufruiu "do capital cultural de duas famílias importantes do fim do Império" (Eleutério, 2005, p. 209). O acesso privilegiado à educação, comum às mulheres brasileiras oriundas de famílias abastadas, permitiu a Bertha ser fluente em alemão e francês, ler obras da literatura mundial e despertar o gosto pela filosofia, em especial por Nietzsche. Bertha escreveu sobre os mais variados temas - de psicologia à poesia de Whitman e Byron, de estética à filosofia de Kant e Nietzsche.

Albertina Bertha fora educada por uma professora alemã, formada pela Escola Normal de Berlim, que o pai mandara buscar especialmente para a sua educação, preocupado com a qualidade e o refinamento da formação da filha. Para Eleutério (2005, p. 209210), "a preceptora foi de importância vital para sua formação e é

1 Sobre a vida do Conselheiro Lafayette e sua significativa participação político-histórica no Brasil, vale a pena consultar Lafayette, um jurista do Brasil, de Maria Auxiliadora de Faria, Lígia Maria Leite Pereira e Paulo Roberto de Gouvêa Medina (2009).

146 | Cad. Nietzsche, Guarulhos/Porto Seguro, v.40, n.1, p. 145-159, janeiro/abril, 2019. 
lembrada nos romances de Albertina". A influência da professora alemã é nítida nas referências à cultura germânica, desde as obras literárias e filosóficas à música clássica. A influência do pai intelectual foi fundamental para a sua formação. Bertha cresceu e viveu entre os livros, teve a oportunidade de uma educação refinada e, principalmente, o incentivo paterno para ler e escrever:

A biblioteca de papai era imensa - informou-me D. Albertina Berta. Estantes de alto a baixo. Eu cresci entre os livros. Aprendi a ler em francês e foi em francês que escrevi os meus primeiros contos. Papai leu-os e me disse: "Você tem intuição literária". Exultei. "Mas precisa conhecer a nossa língua". E deu-me para ler A Morgadinha do Val-Flor. Aborreceu-me o livro. Papai passou-me, então, a Ulisseia, de Pereira de Castro. Depois, eu quis ler Carlyle. Papai não consentiu. A instâncias reiteradas, indicou-me La Philosophie, de Jourdain, para que aprendesse a linguagem metafísica, a introspecção. Data aí o meu amor à filosofia (Barbosa, 1954, p. 136).

Amante confessa da filosofia, Albertina Bertha foi uma das precursoras a estudar Nietzsche no Brasil. Em 1914, integrou o conjunto de doze intelectuais que participaram do prestigiado ciclo de conferências no Salão Nobre do Jornal do Commercio; foi a única mulher conferencista a participar deste ciclo, ao lado de Alcides Maya, Bastos Tigre, Teixeira Leite Filho, Goulart de Andrade, Belisário Soares de Souza, Oscar Lopes, Sebastião Sampaio, Leal de Souza, Pedro Moacyr, Felix Pacheco e Gregorio Fonseca, Albertina Bertha.

Quebrando as expectativas do que era esperado de uma escritora mulher ${ }^{2}$, a conferência de Albertina foi sobre Nietzsche e virou capítulo do livro Estudos, publicado em 1920. Para Eleutério, "a escolha é difícil, visto ser Nietzsche um filósofo dos mais transgressivos, e a questão é apresentá-lo a uma plateia que possivelmente não está

2 "Mesmo educadas, na maioria das vezes não se esperava que elas escrevessem literatura (ou literatura "de qualidade") e muito menos que a publicassem. A educação recebida tinha um fim muito claro, funcionava como mais uma prenda para facilitar o casamento. Das mulheres que escreviam, se esperava textos com fins didáticos e morais, manuais de comportamento para outras mulheres, linguagem fácil, bom mocismo, ficção doméstica e certo recato literário" (Faedrich, 2018b, p. 161). 
preparada para entendê-lo" (Eleutério, 2005, p. 217). A conferência repercutiu na imprensa carioca e o nome de Albertina Bertha ficou muito atrelado ao do filósofo.

Em homenagem da Campanha Nacional de Aviação ao filósofo alemão, um dos quatro aviões de treinamento doados ${ }^{3}$ recebeu o nome de Frederico Nietzsche e foi "batizado" pela "madrinha/paraninfa" Albertina Bertha. No recorte d'O Jornal, de 29 de janeiro de 19494, aparece a foto da escritora carioca na solenidade, cercada de familiares, com uma garrafa de champanhe nas mãos espargindo sobre a hélice do avião. Na reportagem sobre a solenidade, presidida pelo senador Salgado Filho e com a presença de pessoas ilustres da época, fica evidente o prestígio de Albertina Bertha e o seu sucesso como escritora:

Esse aparelho foi batizado pela escritora patrícia sra. Albertina Bertha, filha do conselheiro Lafayette Rodrigues Pereira e viúva do sr. Alexandre Stockler Pinto de Menezes, um dos grandes propagandistas da República. Antiga colaboradora dos "Diários Associados", a sra. Albertina Bertha surgiu na literatura brasileira com o romance Exaltação, verdadeiro sucesso de livraria, que marcou época na história literária brasileira. Poucos escritores tiveram uma estreia tão auspiciosa e marcante como a de Exaltação, que consagrou definitivamente sua autora como uma das legítimas expressões da literatura contemporânea. Outros romances, como Voleta e $E$ ela brincou com a vida, solidificaram o prestígio da escritora que foi madrinha do "Frederico Nietzsche" no "meeting" aviatório, e que publica ultimamente uma série de “estudos" já em seu segundo volume (O Jornal, 29 jan 1949, ed. 08821).

Após batizar o avião e derramar "o simbólico champanhe na hélice do avião", Albertina Bertha "pronunciou o aplaudido discurso" sobre Nietzsche. Abaixo, reproduzo um breve trecho deste discurso:

3 Dois aviões foram doados às cidades portuguesas, Lisboa e Porto, em homenagem à juventude lusitana, recebendo os nomes de "Estácio de Sá" e "D. João VI". Os outros dois, "Frederico Nietzsche", doado para o aeroclube de Valparaíso, em São Paulo, e "Professor Mendes Pimentel", em homenagem ao jurisconsulto, destinado ao aeroclube de Sorocaba.

4 Todas as notícias mencionadas neste texto estão disponíveis na Hemeroteca Digital da Biblioteca Nacional (http://bndigital.bn.gov.br/hemeroteca-digital/).

148 | Cad. Nietzsche, Guarulhos/Porto Seguro, v.40, n.1, p. 145-159, janeiro/abril, 2019. 
A presença de Nietzsche na produção intelectual e literária de...

Este filósofo, eminência do Esteticismo e da Solidão, como todos os fulgores aristocráticos das sensações fortes e todas as virtudes proibidas à mediocridade, ambicionava a grande pausa na beleza e a demência branca dos ascetas. Ele reclamava com tenacidade e entusiasmo outros apogeus, outras eternidades sem deuses, sem recompensas, sem venturas derradeiras, e idealizou o super-homem, essa entidade quase divina que transmuta a sensualidade em ebriezas transcendentes, onde paixões infrenes, o bem, o mal, se agitam, ao grande estilo domina, e a vontade se torna flexuosa, solta de todas as correntes passadas. Imagem de si mesmo, apresenta os característicos que lhe assinalavam a sensibilidade doentia, a dignidade, $o$ orgulho, as excelências de uma mentalidade egregia, possuída do instinto heleno, essa esteidência magnifica da vida. Nietzsche se deificava, gozava de si em erguendo um mundo de ideias e de observações que se estiram à guisa de uma surpresa dionisicamente intelectual na imaginação e no espírito de todos nós (O Jornal, 29 jan 1949, ed. 08821).

No ano seguinte da conferência sobre Nietzsche, Albertina Bertha ministrou outra palestra de assunto diferente, porém foi lembrada pelo sucesso da anterior: "Inaugurou-as, fazendo um admirável estudo da psicologia d'A Criança, a eminente escritora Albertina Bertha, que, na brilhante série do ano passado, encantou o mundo literário e surpreendeu os círculos femininos com um ensaio, verdadeiramente notável, sobre Nietzsche" (Revista Careta, n. 374, 21 ago 1915, grifos meus).

Embora contemporâneas de Albertina tenham desempenhado papel relevante na produção literária daquele período, não era sem obstáculos e hostilidade. Sylvia de Leon, em "Reparos", na Revista Careta, fez uma crítica da crítica à conferência de Albertina Bertha. $\mathrm{O}$ meio literário e intelectual sempre foi muito hostil com as mulheres. Talvez, inclusive, essa hostilidade esteja ligada ao seu gradual desaparecimento da memória e história literárias. As escritoras tiveram de enfrentar casos de desencorajamento por parte de uma crítica que desqualificava - de forma explícita ou velada, com ou sem razão - qualquer produção literária ou intelectual feminina. Em alguns casos, escritoras promissoras abandonaram este ofício. 
Faedrich, A.

Em outros, mulheres tiveram de enfrentar bravamente o menosprezo por parte dos homens (Faedrich, 2018, p. 164-177). Com Albertina Bertha não foi diferente: entre as doze conferências realizadas no Salão Nobre do Jornal do Commercio, em 1914, somente Bertha a única mulher -, recebeu crítica negativa. No artigo publicado na Revista Careta, Sylvia de Leon coloca em xeque a plausibilidade dos argumentos críticos a Albertina Bertha: "Todos os dias escritores e poetas sobem à tribuna das conferências sem que os censores da Sra. Albertina Bertha julguem necessário chamá-los a combate". Conforme Leon, acusaram o excesso de erudição de Bertha - "lamentou que ela mostrasse tamanha erudição e não fosse mais pessoal”. Tal crítica ressoa as palavras de Olavo Bilac à poeta Amélia de Oliveira, na carta que o ‘príncipe dos poetas’ envia para a sua noiva: “[...] há em Portugal e Brasil cem ou mais mulheres que escrevem. Não há nenhuma delas de quem não se fale mal, com ou sem razão" (ELTON, 1954, p. 50). Nas palavras de Bilac, o recado estava claro: a literatura era um espaço interdito às mulheres. De forma homóloga, a crítica velada parecia indicar que a filosofia era interdita às mulheres.

Leon revela, no mesmo texto, ser uma prática comum entre os homens usar pseudônimos femininos para criticar as escritoras:

Pondo ao fim do seu artigo masculino um nome espanhol de mulher, um cavalheiro alvejou com finos gabos e leve ironia a Sra. Albertina Bertha.

No mesmo número em que apareceu esse artigo, a mesma folha que o inseriu, comentando a conferência realizada pela referida escritora, lamentou que ela mostrasse tamanha erudição e não fosse mais pessoal.

É meia noite. Escrevo ao sair de uma festa. Estou fatigada e não pretendo defender minha nobre confreira, porque não me parece que a desonre a acusação de não ser fútil, numa terra em que a futilidade rude dos homens julga com tão impertinente rigor a futilidade adorável das mulheres.

Escrevo estas linhas com o intuito único de frisar uma circunstância que me parece muito significativa.

$150 \mid$ Cad. Nietzsche, Guarulhos/Porto Seguro, v.40, n.1, p. 145-159, janeiro/abril, 2019. 
A presença de Nietzsche na produção intelectual e literária de...

Todos os dias escritores e poetas sobem à tribuna das conferências sem que os censores da Sra. Albertina Bertha julguem necessário chamá-los a combate.

Essas conferências são singelamente noticiadas entre notas banais de louvores.

Os distintos críticos aos quais me refiro, com uma gentileza que o meu sexo lhes agradece, guardavam as suas ironias para a única senhora brasileira incluída na série de conferências literárias realizadas no Rio de Janeiro.

Essa esquisita distinção seguramente não melindrou a ilustre romancista, que tantas provas de apreço recebeu da imprensa brasileira. (Leon, Revista Careta, n. 375, 28 ago 1915, grifos meus).

É interessante observar a falta de sentido na acusação que Albertina sofre por ser "erudita demais" ao apresentar Nietzsche. Não há sentido porque a palestra apresenta uma abordagem panorâmica da vida e obra do filósofo, e, como bem observa Eleutério, "numa linguagem ágil, diversa daquela que encontramos nos dois romances" (2005, p. 217).

Além de um capítulo específico sobre Nietzsche, transcrição da conferência, é frequente na obra de Albertina Bertha epígrafes do filósofo, em francês. Em Estudos ${ }^{5}$, a epígrafe é do livro Assim falou Zaratustra: "Ô mon âme, j’ai enlevé de toi toute obéissance,

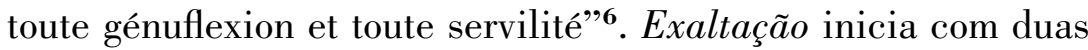
epígrafes, a primeira de Assim falou Zaratustra - "En vérité, pareil au soleil, j'aime la vie et toutes les mers profondes" - e a segunda de $A$ vontade de potência:

Thèse : tout ce qui est considéré comme bien, c'est le mal d'autrefois que l'on a asservi. Mesure : plus sont grandes et redoutables les passions qu'une époque, un peuple, un individu, peuvent se permettre parce qu'ils peuvent

5 Estudos é composto por 1. Nietzsche; 2. A criança; 3. A mulher na guerra; 4. Notas de filosofia: indução, princípio de causalidade; 5 . Estética contemporânea; e 6.0 romance (a sua evolução).

6 Alma minha, afastei de ti toda a obediência, toda a genuflexão e todo o servilismo - tradução de José Mendes de Souza. 
Faedrich, A.

s'en servir comme de moyens, plus leur culture se trouve à un niveau élevé. Plus un homme est mediocre, faible, servile et lâche, plus il fera de mal : chez lui le royaume du mal est le plus étendu. L'homme le plus bas verra partout le royaume du mal (c'est-à-dire de ce qui lui est interdit et hostile) ${ }^{7}$.

Nos capítulos IX e X do romance, duas epígrafes de Nietzsche, igualmente em francês: "L'âme noble prend comme elle donne, par un instinct d'équité passionée et violent qu'elle a au fond d'elle-même" e "Ce qui se fait par amour se fait toujours por delà le bien et le mal".

Exaltação é o romance de estreia da autora carioca, publicado em 1916, e apresenta uma protagonista inconformada com o papel atribuído à mulher e com a hipocrisia e preconceito da sociedade. Ladice quer abolir os costumes arraigados na ignorância, quer uma sociedade em que a inteligência da mulher possa ser reconhecida, dando, assim, a oportunidade de ela interagir ao nível dos homens. Voz dissonante na belle époque brasileira, Albertina Bertha criticou a condição feminina de seu tempo e demonstrou inconformismo com a sociedade patriarcal; defendeu a educação das mulheres; escreveu romances com ousadia temática em temas-tabu como o adultério e o desejo feminino; viu a leitura de seus romances proibida na própria família; foi considerada corruptora de costumes por vozes conservadoras à época. Entretanto, e talvez por isso, viu o sucesso - e as seis reedições - de seu primeiro romance.

O excerto a seguir apresenta o diálogo entre Ladice, personagem transgressora, e sua prima Dinah, protótipo da mulher pura e bemcomportada. Dinah é passiva e obedece ao status quo. Ladice sente-se inconformada com a "trilha comum" que espera das mulheres um comportamento sem inclinações e opiniões. O caráter transgressor da

7 Tese: tudo o que é considerado como bem, é o mal de outrora que se dominou. Medida: quanto maiores e temíveis as paixões que uma época, um povo, ou um indivíduo, podem se permitir porque podem aproveitá-las como meio, tanto mais elevada lhes será a cultura. Quanto mais medíocre, fraco, servil e covarde o homem, tanto mais verá o mal: nele é mais extenso o reino do mal. O homem mais baixo verá em toda a parte o reino do mal (isto é, do que lhe é interdito e hostil).

152 | Cad. Nietzsche, Guarulhos/Porto Seguro, v.40, n.1, p. 145-159, janeiro/abril, 2019. 
protagonista é associado à forma como ela fora educada, às leituras clássicas e fortes:

- Como me irrita essa tua passividade, aprendida em um convento. Aqui, em casa, esqueceu-se de que sou mulher... Querem-me sem inclinações, sem opinião, igual a todos. Meu Deus! É preciso que eu siga a trilha comum, que diga sim, após o sim de toda uma geração, que tenha o pensamento que vinte mil cérebros já elaboraram...

- Bem se vê que foste educada por uma estrangeira protestante; se soubesses mais de religião, não serias assim... Há instantes em que me fazes medo - observou sua prima timidamente.

- É simplesmente efeito de uma natureza tropical e de leituras clássicas, fortes. Qu'importa, Dinah, que seja a primeira a rasgar os preconceitos e as hipocrisias? Querida, tudo evolui. Mulher hoje é espírito até nos gestos; é breviário dos deuses, entendes? (Bertha, 2015, p. 20)

Intelectual, questionadora, avessa às expectativas de uma sociedade conservadora e machista, a protagonista não quer ser mãe, não quer casar sem amor, prefere se dedicar à escrita e à leitura de literatura e filosofia:

[...] Creio não possuir qualidade alguma que me recomende como futura mãe de família... Adoro a paz, a solidão, as coisas estranhas... Sou extremamente independente. Gastarei dias a ler, estudar... Rio-me muito, digo tolices; mas também tenho melancolias impenetráveis, que me roem as próprias fontes de existência; é-me um mal ingênito (Bertha, 2015, p. 68).

Por reconhecer a hipocrisia da sociedade, sente-se em desacordo com os preceitos desta e quer ser livre, agir de maneira fiel às suas vontades. A ousadia do romance está presente sobretudo nos encontros amorosos dos amantes Ladice e Teófilo. Ambos são casados, mas se apaixonam e se encontram de forma clandestina para a realização do amor: 
Faedrich, A.

— Não te deixarei partir, ficarás aqui comigo, ao meu lado, não nunca mais me abandonarás... Nunca mais... - Dizendo isso, ele apertava-a loucamente, cingi-a com os braços, numa exaltação extraordinária.

Ladice, ainda vencida pela veemência de sua sensibilidade, não podia falar, e retribuía esses excessos de amor com afagos lentos, com beijos longos, deliciosos, que nunca acabavam, beijos ardentes que deixavam, de cada vez, um pouco de seu coração, de sua alma, de sua ternura. [...] Ladice, ao seu lado, como uma grande sombra, ninava-o, cantava baixinho, apertava-o, rosto contra rosto, beijava-lhe silenciosamente, pausadamente, o canto dos olhos, das orelhas, os cílios, os cabelos, espalmava-lhe as mãos pelo dorso, como se este gesto quisesse abrange-lo por inteiro, absorvê-lo em si [...] (Bertha, 2015, p. 143-144).

Além das referências explícitas a Nietzsche nas epígrafes, é possível encontrar algumas noções nietzschianas ao longo de Exaltação. O narrador faz menção à noção de rebanho - "le troupeau de Nietzsche", chamando a atenção para o diferencial da personagemprotagonista:

Essas pessoas caminhavam sempre sem parar, como que perfazendo um dever, uma obrigação; umas atrás das outras, enfileiradas, cabisbaixas, inexpressivas, de uma docilidade autômata e enervante que até fazia lembrar de "le troupeau" de Nietzsche. Ladice, no meio d'esse povo, que antes parecia um rebanho tranquilo e pacífico, via a sua superioridade aumentar, duplicar, elevar-se. Tinha consciência de trazer em si faculdades divinas, fragmentos de transcendência, culminâncias, valores extraordinários... (Bertha, 2015, p. 128, grifo meu).

Na sequência, aparece a noção de "eterna quietude" proferida por Ladice. Nesta passagem, a personagem está com o seu amante, Teófilo, planejando uma possível viagem do casal apaixonado a Petrópolis, onde finalmente estariam sozinhos:

No dia seguinte a Senhora de Assis participou a Teófilo a próxima viagem de seus pais a Europa e a sua projetada ida para Petrópolis.

154| Cad. Nietzsche, Guarulhos/Porto Seguro, v.40, n.1, p. 145-159, janeiro/abril, 2019. 
A presença de Nietzsche na produção intelectual e literária de...

- Lá nesse cenário maravilhoso estaremos acima de todas as coisas, seremos o nosso próprio céu, o nosso campanário azul, a nossa eterna quietude, como bem diz Nietzsche... (Bertha, 2015, p. 154)

Em outra cena, Ladice cita Nietzsche novamente. Trata-se de uma passagem em que ela está com o primo enciumado, João Dalmada. Ele é um dos inúmeros homens que aparecem no romance com interesse na jovem. Quando soube que Ladice estava apaixonada por outro homem, passou dos galanteios a conselhos moralistas para a prima:

- O que te falta é mais coerência, mais senso, mais reflexão, mais sinceridade...

Ladice não se zangou, atribuiu essa censura ao rancor do sexo, ou quiçá, ao despeito e, cheia de hilaridade, replicou:

- Se eu fosse assim, deixaria de ser a mulher que tanto aprecias. Nietzsche diz que o nosso maior encanto repousa justamente nesses defeitos... Ele nos não concebe sem a mobilidade das paix̃̃es... - E a sua boca abrindo-se para o riso mostrava pétalas de jasmins.

- Deixemos o filósofo alemão e as suas teorias... A senhora casada deve ser modesta, simples, retraída... Deve-se abster-se de tudo... (Bertha, 2015, p. 166, grifos meus).

É possível relacionar essa passagem do romance com o que Albertina escreveu no ensaio sobre Nietzsche, sobretudo à "vingança de um despeitado" e às "chicotadas de quem nunca foi amado", reações similares entre o primo enciumado e Nietzsche:

Nietzsche não teve de nós outras, mulheres, uma opinião cabal, exata; apenas beirou a realidade da nossa estrutura moral. As suas referências são sombras ocas, ironias para provocar o sorriso, ou, talvez, vinganças de despeitado, floração de mau humor... são chicotadas de quem nunca foi amado, de quem nunca recebeu o carinho, a meiguice, a febre de uma mulher de espírito e beleza. [...] quer-nos mentirosas, ignorantes, sem profundezas de engenho, apenas uma gata perigosa e bela, para a sedução 
Faedrich, A.

do homem... entretanto, as duas únicas mulheres que amara, eram duas intelectuais, dois seres de mistério e de contradições magníficas (Bertha, 1920, p. 28).

Estudos $^{8}$ (segunda série, 1948) apresenta epígrafe de Nietzsche, de Assim falou Zaratustra: "Je porte en moi cette joie du chercheur, cette joie qui pousse la voile vers l'inconnu, s'il y a dans ma joie une joie de navigateur"9. Neste segundo livro de ensaios, não há um capítulo especial para Nietzsche, entretanto, o filósofo é mencionado nos ensaios a título de comparação com os outros filósofos. No capítulo 7, "Kant e a sua filosofia", Albertina Bertha afirma estudar Kant em homenagem a seu pai, o Conselheiro Lafayette:

Em escrevendo sobre KANT estava em Papai (Cons. Lafayette) a me recordar vivamente do entusiasmo, da admiração, estima e respeito que tributava a esse filósofo de nítidas afinidades com ele: ambos profundos e graves se bastavam a si mesmos, ambos de sumo e raro engenho eram donos de uma cultura excessivamente vasta e sólida.

Estudei KANT em homenagem ao Papai, o primeiro que em mim incutiu, por esse sábio, uma exaltação eterna (Bertha, 1948, p. 211).

Bertha aproxima Kant de Nietzsche, fazendo uma espécie de análise comparada entre os dois filósofos:

KANT, NIETZSCHE - e estremecemos diante dessa aproximação. Que há em o filósofo de Königsberg que me traz a Nietzsche? Será porque o amo demasiadamente como pensador e analista que me ensinou a desvendar as visagens, inumeráveis da vida, e a me apossar dos aspectos os mais complexos da humanidade?

8 Composto por dez capítulos: 1) Walt Whitman; 2) Psicologia e moral social; 3) Psicologia existencialista; 4) Psicologia aplicada; 5) Psicologia do artista (Influência de Bergson); 6) Carta do prof. R. Poirier, da Sorbonne; 7) Kant e a sua filosofia; 8) (Fausto) Goethe; 9) Como tornamo-nos interessantes; e 10) Lord Byron.

9 "[Se] existe em mim essa paixão investigadora que impele a vela ao desconhecido; se há na minha paixão um tanto de paixão navegante" (tradução José Mendes de Souza).

156 | Cad. Nietzsche, Guarulhos/Porto Seguro, v.40, n.1, p. 145-159, janeiro/abril, 2019. 
A presença de Nietzsche na produção intelectual e literária de...

KANT, NIETZSCHE - sinto a diferença incisiva que os separa, diferença não só temperamental como espiritual. KANT exclama - arranca as paixões e triunfarás. NIETZSCHE responde - Espiritualiza-as. Sem a ebriez, a tua alma de artista se contrairá. (Bertha, 1948, p. 209).

No capítulo 5, ao analisar Bergson, Bertha faz novas comparações, sendo Nietzsche o filósofo mais citado pela escritora em toda a sua obra:

BERGSON evidencia uma forte propensão para permutar valores e atribuições, tem por hábito repudiar ou transmutar sem necessidade interpretações e denominações já consagradas e sancionadas pela Filosofia. Ao tratar do absoluto, dissolve-lhe a reverência excelsa de ser uno, imutável, todo-poderoso e proclama-o "movimento", "princípio interno" das coisas, "consciência". [...] Não entretém como NIETZSCHE a preocupação de distinguir "elite do rebanho" com os respectivos privilégios e concessões, volve-se para todas as classes, reclama uma agremiação de estetas, de pessoas arrogantes e cultas. [...] BERGSON não pertence à classe dos homens subterrâneos de que nos fala NIETZSCHE (Bertha, 1948, p. 117-163).

Da mesma forma, é possível rastrear inúmeras epígrafes e referências a Nietzsche nos romances Voleta (1926) e E ela brincou com a vida (1938). Se a leitura que Albertina Bertha faz de Nietzsche é adequada ou equivocada, não sou apta a avaliar por não ser da área de filosofia, muito menos especialista em Nietzsche. Minha intenção neste artigo, como leitora de Nietzsche e de Albertina Bertha, foi apresentar 1) a escritora Albertina Bertha, integrante da minha pesquisa sobre literatura de autoria feminina na belle époque brasileira, e 2) como Nietzsche é uma figura central em sua vida e obra. São muitas referências ao filósofo. Elas aparecem excessivamente nas epígrafes de todos os livros de Albertina Bertha; nas falas das personagens literárias, que citam o filósofo, fazem alusão às noções nietzschianas e incorporam a sua teoria no modo de viver; na conferência proferida no Salão Nobre do Jornal do Commercio em 1914 e publicada como primeiro capítulo de Estudos (1920); no 
Faedrich, A.

batizado do avião Nietzsche; nas entrevistas e em outras matérias publicadas na imprensa periódica. Nietzsche é o filósofo de cabeceira de Albertina Bertha. O papel que a escritora desejou desempenhar na sociedade conservadora de sua época tem afinidade eletiva como o espírito vanguardista do pensador alemão.

\title{
Nietzsche's Presence in the Intellectual and Literary Production of Albertina Bertha
}

\begin{abstract}
In this text I analyze the presence of the philosophy of Nietzsche in the literary and intellectual work of the writer Albertina Bertha de Lafayette Stockler (Rio de Janeiro, 1880-1953). The interest and passion of the writer by the German philosopher is demonstrated in references, epigraphs and quotes of the philosopher. Nietzsche's discussion of Bertha holds a historical interest in the fact that it is rare for a woman to attend philosophical forums on an equal footing with men in Brazil at the time. In addition to the celebrated 1914 conference, which became the chapter in Estudos (1920), Nietzschean notions permeate the writings of Albertina Bertha, both in novels and essays.
\end{abstract}

Keywords: Nietzsche, Albertina Bertha, Brazilian literature, Philosophy.

\section{Referências}

BARBOSA, Francisco de Assis. Lafayette Rodrigues Pereira visto por D. Albertina Berta. In: . Retratos de Família. Rio de Janeiro: José Olympio, 1954, p. 131-140.

BERTHA, Albertina. Exaltação. Organização de Anna Faedrich. Porto Alegre: Gradiva, Rio de Janeiro: Fundação Biblioteca Nacional, 2015.

BERTHA, Albertina. E ela brincou com a vida. Rio de Janeiro: Borsoi, 1938.

BERTHA, Albertina. Voleta. Organização, atualização e notas Geysa Silva. Rio de Janeiro; Brasília: INL - Instituto Nacional do Livro, 1987.

158 Cad. Nietzsche, Guarulhos/Porto Seguro, v.40, n.1, p. 145-159, janeiro/abril, 2019. 
BERTHA, Albertina. Estudos. $1^{\text {a }}$ série. Rio de Janeiro: Jacintho Ribeiro dos Santos Editor, 1920.

BERTHA, Albertina. Estudos. $2^{\text {a }}$ série. Rio de Janeiro: A. Coelho Branco F ${ }^{\circ}$ Editor, 1948.

ELEUTÉRIO, Maria de Lourdes. Vidas de romance: as mulheres e o exercício de ler e escrever no entresséculos. 1890-1930. Rio de Janeiro: Topbooks, 2005.

ELTON, Elmo. O noivado de Bilac. Com a correspondência inédita do poeta à sua noiva - D. Amélia de Oliveira. Rio de Janeiro: Organização Simões, 1954.

FAEDRICH, Anna. Memória e amnésia sexista: repertórios de exclusão das escritoras brasileiras. Letrônica, Porto Alegre, vol. 11, n. supl. (supl. 1), setembro 2018, p. 164-177. Disponível em: http://revistaseletronicas.pucrs. br/ojs/index.php/letronica/article/view/30477/17321. Acesso em: 17 nov 2018.

FAEDRICH, Anna. Vozes dissonantes, vozes abafadas: literatura brasileira de autoria feminina na belle époque. In: DIAS, André, PASCHE, Marcos, RAUER, Rauer Rodrigues (Orgs.). Literatura e dissonâncias. $1^{\mathrm{a}} \mathrm{ed}$. Rio de Janeiro: ABRALIC, 2018b, p. 159-173.

LEON, Sylvia de. “Reparos”. Revista Careta, n. 375, 28 ago 1915. Disponível em: http://memoria.bn.br/DocReader/docreader.aspx?bib=083712\&pasta=ano\%20 191\&pesq=Sylvia\%20de\%20Leon. Acesso em: 10 nov 2018.

Artigo recebido para publicação em 12/10/2018 Artigo aceito para publicação em 20/01/2019 